\title{
The Progressive response of Sahelian Dams to Sediment Intrusion: Case of Kano State Between 1976 and 2009.
}

\author{
Mahadi Lawan Yakubu ${ }^{1,3, a^{*}}$, Usman Tasiu Abdurrahman ${ }^{2,3, b}$, \\ Muhammad Tajuri Ahmed ${ }^{3, \mathrm{c}}$, Amina Sallau Aliyu ${ }^{3, \mathrm{~d}}$, Muttaqa Uba Zango ${ }^{3, \mathrm{e}}$, \\ Ali Sani Maihula ${ }^{3, f}$ \\ ${ }^{1}$ Institute of Environmental and Water Resources Management, Universiti Teknologi Malaysia, \\ 81310 Skudai, Johor, Malaysia \\ ${ }^{2}$ Faculty of Civil Engineering, Universiti Teknologi Malaysia, 81310 Skudai, Johor, Malaysia. \\ ${ }^{3}$ Department of Civil Engineering, Faculty of Engineering, Kano University of Science and \\ Technology, Wudil, Kano, Nigeria \\ amahadilawan@gmail.com, busmantee@gmail.com, 'amtajuri@yahoo.co.uk, \\ 'meenasal@yahoo.com, ${ }^{\mathrm{e}}$ muttaqaubaz@yahoo.com, ${ }^{\mathrm{f}}$ maihulaa@yahoo.com,
}

Keywords: Dam sedimentation, Kafin-chiri, Kano, Magaga, reservoir function, reservoir capacity, Thomas.

\begin{abstract}
Reservoirs are built to store water during abundance for possible reuse during scarcity; sediment incursion is the leading phenomenon that limit reservoirs to sustain this function. Therefore, modelling the rate at which reservoir accumulates sediments is critical in understanding the nature of the problem, the time frame within which it is expected to occur, and the best mitigation strategy that will maintain the reservoir service. This study investigated the sediment influx in three typical Sahelian reservoirs in Kano state using the bathymetric method. The reservoir capacities were found to be declining at different rates but with grave consequences on the future, and economy of the state. In prolific terms, the state is losing 490 million litres of water storage each year. Presently, Magaga lost 39\% of its capacity; Thomas has lost 13\%; while Kafin-chiri has lost 5\%. For sustainability, this trend needs to be addressed. The short and long-term best management strategies to curtail this trend have been outlined in this study.
\end{abstract}

\section{Introduction}

Reservoir capacity loss is the foremost problem that affects reservoir function. Reservoir performance is deemed impaired if half of its capacity is lost to sedimentation [1]. Although, other serious problems related to sedimentation could appear even at a small loss of capacity. The functionality of a reservoir continues to be threatened as the reservoir ages with unceasing accumulation of sediments. Modelling of reservoir sedimentation and dregs management often requires a site-specific study; a specific site can give an insight into its complex nature and could provide a pointer for best management approach. The objective of this study is to investigate the sediment yield in a typical Sahelian climate of Kano, West Africa. The potential effects of these accumulated sediments on reservoir capacities and its implication on economic activities was also discussed.

Sediment influx and their deposit are the key factor that accelerates the impairment of a reservoir's useful life [1,2]. Accumulation of sediments in reservoirs changes its morphological formation overtime [3]. Dam's sedimentation if not properly monitored and appraised could result in a reservoir reduced capacity, bed incision, and ultimately result in collapsed of a downstream bank [2]. Maintaining existing reservoir has no sustainable substitutes; reservoirs are built on the most viable sites to dam specific catchments, therefore, maintaining reservoir capacity to minimise sediment deposit by accurately estimating future load of sediments is not negotiable. Sediment deposit can be accelerated or decelerated based on the rainfall intensity, nature of soil, vegetation cover and topography of the catchment area $[4,5]$.

The annual rate of sediment transfer to a reservoir is proportional to the yearly rainfall [6] and could vary with time $[2,7]$. Two of the most important factors that have direct bearing on the 
sediment influx rate are land-use changes in the upstream due to anthropogenic activities [3, 6] and the reduced trap efficiency of the reservoir [3, 8]. Nguyen et al [7] noted 64\% decrease in sediment yield into Son Tay reservoir within the first twenty-seven years of its service. The presence of sediments in a reservoir also deteriorates water quality and increases the risk of eutrophication thereby threatened the aquatic life [9].

\section{Study Area.}

Kano is located in the Sahelian region of West Africa; it lays on latitude $11^{\circ} 30^{\prime}$ north and longitude $8^{\circ} 30^{\prime}$ east. It is the most populous state in Nigeria [10]. The current population of Kano on a head count is more than that of Belgium, Chad, Tunisia or Greece and twice that of Singapore, Jordan, Lebanon, Denmark or Finland. Kano state being the largest commerce centres in West is attracting numerous people to settle; thereby exacting pressure on its meagre water resources.

Kano state largely lies on the basement rock complex; therefore, the amount of water for domestic and agricultural use had to come from surface water [11]. Currently, it holds the largest concentration of earth dams in Nigeria [12]. The most strategic of these dams were conceived and constructed between 1968 and 1980 [13]. Among them are the Thomas, the Kafin-chiri and Magaga dams.

\section{Description of reservoirs}

Table 1 summarises the basic characteristics of Thomas, Kafin-chiri and Magaga dams. The location map of these dams was shown in Fig.1, and the present contour of each reservoir is presented in Fig. 2(a), 2(b), and 2(c) respectively for Thomas, Kafin-chiri and Magaga.

Table 1: Characteristics of Thomas, Kafin-chiri and Magaga dams [14, 15]

\begin{tabular}{lcccccc}
\hline Dam & $\begin{array}{c}\text { Reservoir } \\
\text { capacity } \\
(\mathrm{MCM})\end{array}$ & $\begin{array}{c}\text { Active } \\
\text { capacity } \\
(\mathrm{MCM})\end{array}$ & $\begin{array}{c}\text { Dead } \\
\text { storage } \\
(\mathrm{MCM})\end{array}$ & $\begin{array}{c}\text { Reservoir } \\
\text { Area } \\
\left(\mathrm{Km}^{2}\right)\end{array}$ & $\begin{array}{c}\text { Catchment } \\
\text { Area }\left(\mathrm{Km}^{2}\right)\end{array}$ & $\begin{array}{c}\text { Commissioned } \\
\text { year }\end{array}$ \\
\hline Thomas & 60.30 & 56.60 & 3.70 & 15.0 & 585 & 1976 \\
Kafin-Chiri & 31.12 & 24.60 & 6.52 & 8.4 & 225 & 1977 \\
Magaga & 19.63 & 17.22 & 2.41 & 3.7 & 119 & 1980 \\
\hline
\end{tabular}

Thomas dam was commissioned in 1976 with a total reservoir capacity of $60.30 \mathrm{MCM}$, out of which 3.7MCM was a dead storage. It was intended for water supply, fisheries, irrigation, wild life conservation and recreation. Runoff drains to the reservoir from a catchment of $585 \mathrm{Km}^{2}$ from a confluence of three streams, the Tomas, Gembe and Boko, in addition to a spring from the neighbouring rock. At its deepest section, the embankment is $13.7 \mathrm{~m}$ deep with a base width of $12.8 \mathrm{~m}$ and the crest length span $5.3 \mathrm{~km}$.

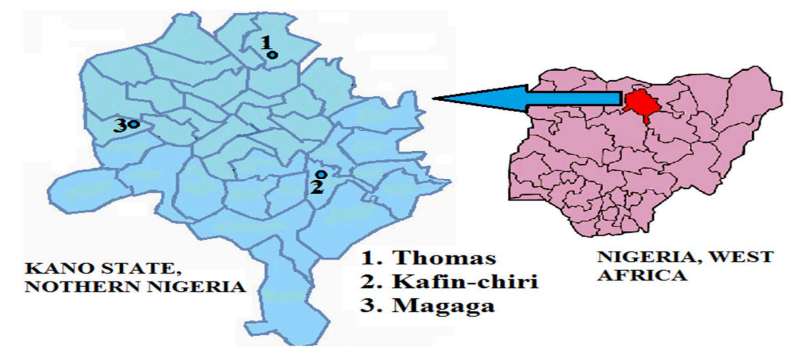

Figure1: The location map of Thomas, Kafinchiri, and Magaga Dams

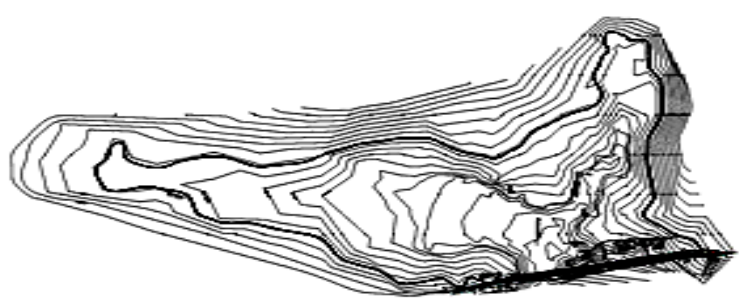

Fig. 2(a): present contour of Thomas 


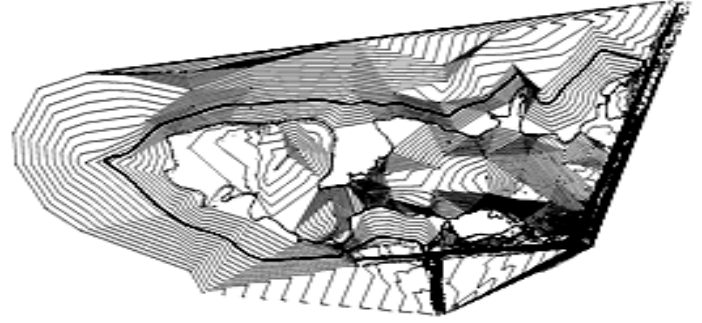

Fig. 2(b): present contour of Kafin-chiri

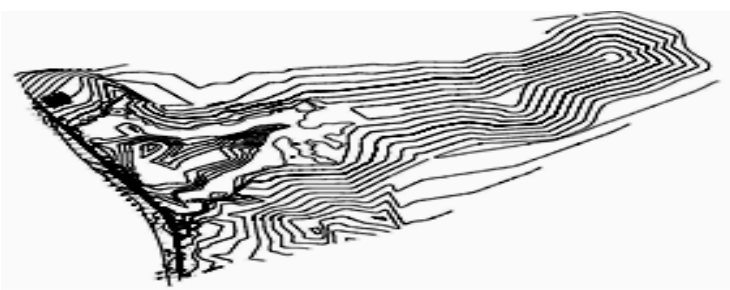

Fig. 2(c): present contour of Magaga

\section{METHODOLOGY}

The present geometrical shape and depth of the reservoirs were obtained using the hydrographical survey method. The vertical and horizontal distances were obtained using a geographic positioning system (GPS) and a calibrated line. The use of GPS in the hydrographic survey is known to speedup data acquisition, and improve its accuracy and efficiency [16]. In addition, it also made data processing much easier. The vertical depth was measured using a handheld graduated lead line, while the parallel distances were measured using a differential GPS. The depth of the water at each point was obtained by lowering the calibrated line in every 5 to $10 \mathrm{~m}$ horizontal distances, and the GPS was used to record the global positioning of each point. It was made sure that the calibrated line touches the bottom of the reservoir before any reading was called and recorded. The total station was used to capture additional data from the offshore area and also verified the existing benchmarks and established necessary control points. The data obtained was downloaded into a computer and processed using CivilCAD ${ }^{\circledR}$.

The present capacity of each reservoir was estimated from the generated contour maps. Due to nonlinearity of contours, the area enclosed by each contour line was measured using a computer aided application. The Trapezoidal method was used in this study to calculate the differential volume of water impounded between two successive known contour areas. The trapezoidal formula provided flexibility of use and its extended application when the contours are segmented into manageable units.

\section{Result and Discussions}

The contour heights and intervals were not the same for all the dams. The heights were reduced in reference to the established reference level at the dam and related to the mean sea level (MSL), while the contour intervals were chosen to suit the size of the reservoir for better presentation during the data processing. The new reservoir volumes for each Dam were calculated and presented in Table 5.

The present reservoir capacities were compared with the initial dam capacity for each dam. The difference between the two gave the capacity loss due to sedimentation. The computed results were presented in Table 5. The percent reduction is an indicator of the volume of sediment deposited in each reservoir.

Table 5: The present Reservoir Capacities ( in MCM)

\begin{tabular}{cccccc}
\hline Dam & $\begin{array}{c}\text { Initial } \\
\text { Capacity }\end{array}$ & $\begin{array}{c}\text { Present } \\
\text { Capacity }\end{array}$ & $\begin{array}{c}\text { Reduction } \\
\text { Capacity }\end{array}$ & $\begin{array}{c}\text { Percent } \\
\text { Reduction }\end{array}$ & $\begin{array}{c}\text { Storage } \\
\text { depletion/year }\end{array}$ \\
\hline Thomas & 60.30 & 53.24 & 7.06 & 12 & 0.36 \\
Kafin-Chiri & 31.12 & 29.64 & 1.48 & 5 & 0.16 \\
Magaga & 19.63 & 13.10 & 6.53 & 33 & 1.12 \\
\hline
\end{tabular}

Table 5 indicated that over the life time of each of the dams, there has been in flow of sediments into the reservoir thereby causing a shortfall from the initial capacity. The sediment deposition in Magaga reservoir has reached an unprecedented level that could compromise the reservoir function, followed by Thomas with $12 \%$ capacity reduction. Kafin-chiri has peered well among the reservoirs 
considered in this study, there was only 5\% capacity reduction for its thirty-two years of existence. The global average loss of active reservoir capacity due to sedimentation is $50 \%$ spanning over twenty-five years for $10 \%$ of the dams surveyed by world commission of dams [17]. The report stipulates that the dams that are located at the lower reach of rivers are more prone to higher sedimentation flow.

Researchers differ on the trend of sediment accumulation in reservoirs. Some maintained that the initial accumulation rate is much higher [7], others maintained it is fairly uniform [17] but affected by the yearly rainfall [8]. The world commission of dams [17] found that the active capacity of world's dams begins to decline at the onset of two and half years. Generally, the rate of sedimentation of small dams is higher than larger dams. Data surveyed from forty two dams in Morocco indicated that active reservoir capacity is depleting at a rate of $1.1 \%$ for smaller dams with reservoir volume of $500 \mathrm{~m}^{3}$ and $0.6 \%$ for reservoir with higher volume [17]. The dams considered in this study are categorised as large dams (dams having a minimum reservoir capacity of $1 \mathrm{MCM}$ or having a deepest section greater than $15 \mathrm{~m}$, or a height of $10-15 \mathrm{~m}$ but with a $\geq 500 \mathrm{~m}$ crest length). The result from this study supported the world commission of dams' [17] conclusion on the rate of reservoir depletion based on their classification. Thomas dam with formative reservoir capacity of $60.30 \mathrm{MCM}$ is depleting at the rate of $0.36 \%$ ( $0.21 \mathrm{MCM}$ per year) over its useful life of 33 years. Kafin-Chiri with initial active storage of $31.12 \mathrm{MCM}$ at the time of commissioning in 1977 is now depleting at the rate of $0.16 \%$, while Magaga is being depleted at the rate higher than global average. The loss of reservoir capacity of these economical dams is of serious concern. Thomas and Magaga are losing 0.21 and $0.23 \mathrm{MCM}$ each year respectively; while Kafin-chiri is losing 0.05 MCM each year. In productive terms, the state is losing $0.49 \mathrm{MCM}$ per annum of water storage for drinking and irrigation from just three of its twenty five dams. This could be disastrous with the expulsion of its population.

Sedimentation potentially undermines the performance of dams. The world commission of dams [17] reported that between $0.5-1 \%$ of the worlds impounded fresh water in the existing dams is lost consistently to sedimentation in both large and small dams, and the report further estimated that $25 \%$ of the current planet's fresh water may be lost within the accompanying 11 to 36 years, if good control measures to stall sedimentation were not implemented.

Regression analysis was performed to estimate the effect of sediment incursion into the reservoirs based on the data presented on Table 5. Due to lack of continuous yearly sediment loss records, it is assumed that the rate of sediment flow is proportional to the yearly rainfall. The yearly rainfall of the state is fairly declining at a uniform rate [18]. Therefore, the loss of reservoir capacity was assumed to flow a linear model.

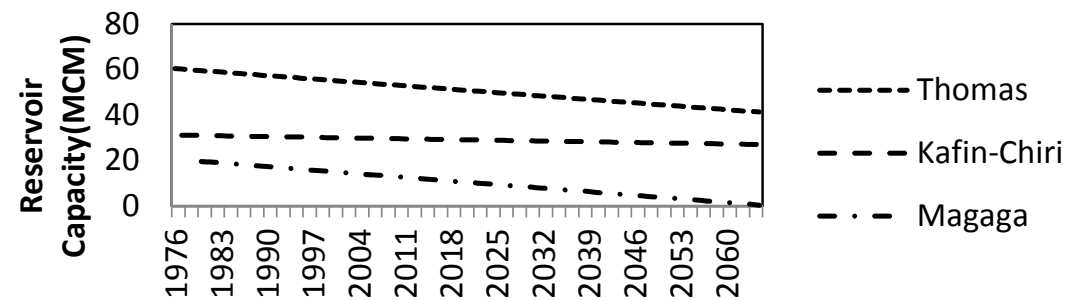

Fig. 4 is the modelled loss of capacity of the three dams studied in this research, based on equation 1-3

Fig. 4 shows that at this current rate of reservoir depletion, Magaga would lose its useful storage by 2024. The present reservoir capacities stand at 53.20, 29.64 and 13.1 MCM correspondingly for Thomas, Kafin-chiri and Magaga; this indicated a total combined loss of 17.5 MCM. The expected loss by year 2020 for Thomas, Kafin-chiri and Magaga would be 19.4, 1.99, and 9.0 MCM respectively. It is instructive to note that there would be an integral loss of 20.4 MCM by year 2020 from these reservoirs. This loss would be more than the formative capacity Magaga dam. By the year 2042, the integrated loss in the three reservoirs would be more than the commissioning capacity of Kafin-chiri dam. By 2065, the state is predicted to lose $42.25 \mathrm{MCM}$ from the joined 
capacity losses of 32, 13 and 98\% from Thomas, Kafin-chiri and Magaga reservoirs respectively. This loss is equivalent to the present integrated capacities of Kafin chiri and Magaga dam.

Fig. 5 is the modelled active reservoir capacity loss, and Eq. 1 is the numerical representation of the model. As indicated in Fig.5, currently Thomas has lost 13\% of its capacity; Kafin-chiri has lost $5 \%$, while Magaga has lost 39\%, this translates to total depletion of $17.5 \mathrm{MCM}$ thus far. By year 2020 , the state would be deprived of a whopping $20.4 \mathrm{MCM}$, corresponding to $16 \%$ loss of Thomas, $6 \%$ loss from Kafin-chiri and 46\% loss from Magaga reservoirs. Magaga has lost 30\% of its capacity since 2006 , and presently the capacity loss stands at $39 \%$, and successively it is expected to lose $50 \%$ of its formative capacity in the next 10 years. In the ensuing 10 years, Thomas would lose $17 \%$ of its commissioning capacity and gradually would lose $30 \%$ by 2060 . Magaga reservoir has lost $2 \%$ of its capacity within just two years (1982) after its operation, the same percentage was lost by Thomas in the same year, but within a longer period of six years, Kafin-chiri attained $2 \%$ loss after 11 years. This is indicative of the rate of sediment inflow to the reservoirs, and could be clearly deduced from the slope of each reservoir presented in Fig.5. The decline in capacity of the three dams under study appears at a different time in their operational years. All the three dams indicated an initial $1 \%$ decline in their capacities after one year of operation, but thereafter, the rate remarkably accelerated. It took Magaga only four years after its operation to lose 5\% of its capacity, it took Thomas thirteen years after commissioning to lose $5 \%$ of its capacity, while it took thirtyone years for Kafin-chiri to lose $5 \%$ of its capacity. This type of reservoir depletion rate was a serious threat to the sustainability of the reservoir [5]

$R_{x}=R_{0}-k L$

$k=x-1975$

Where $R_{x}$ is reservoir loss in MCM corresponding to $x$ calendar year, $R_{0}$ is the initial reservoir capacity (MCM), $k$ (years) is Reservoir Constant as given in Eq. 2 , and $L$ is the Sediment accumulation rate $\left(\mathrm{MCM} \mathrm{y}^{-1}\right)$. The $L$ values for Thomas, Kafin-chiri and Magaga reservoirs were $0.205,0.042$ and $0.177 \mathrm{MCM} \mathrm{y}^{-1}$ respectively.

In the next 51 years period, the reservoir capacities of the state would be taken back to their statues in 1976. This portrayed grave danger giving its current population size, which is appreciating at $3.5 \%$ yearly [10]. With decreased rainfall depth, and an exploded population alongside the reduced dam's capacities poses a great threat to the sustainability of available water for domestic and agronomic purposes. Desirably, the impounded attainable fresh water for agricultural and domestic uses should appreciate at least at the same rate with the population growth indices.

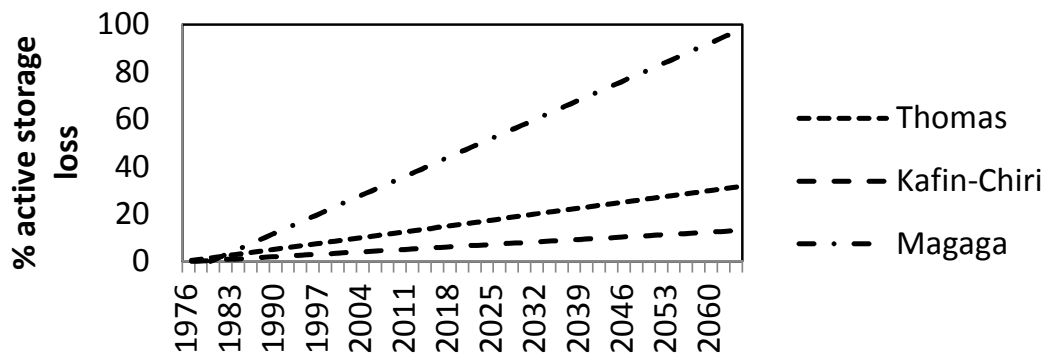

\section{Conclusion}

From this study, it was clear that, not only are the dams in Kano aging, but they are also losing their social and economic values. An intervention is needed to reduce the sediment inflow to Kano dams, especially, the Magaga dam, as quickly as possible. The rate of sedimentation of the Magaga dam was above the world average, while the rate of sedimentation in Thomas and Kafin-chiri were within the world brackets. The state is losing 490 million litres of water storage for drinking and irrigation yearly from just three of its twenty five dams. This could be disastrous with the expulsion of its population and declining reservoir capacity. 
The state needs to device both technical and management strategies that will limit and slowdown the transportation of sediments into its reservoirs. In the short term, limiting soil erosion from the reservoirs' catchment areas should be given a priority; this could be achieved by construction of sediment entrapment structures at the off-stream. The second short term measure, could be the removal of sediments in the reservoirs by hydrosuction or by mechanical dredging. Reservoirs don't last forever, therefore, in the long term; there is a need for the construction of additional reservoirs, which will incorporate a sediment equilibrium balance. The viability of these recommendations would most likely depends on hydrological, physical, and financial parameters. Therefore, there is a need to further study the effect of sediment erosion in these reservoirs at catchment scale.

\section{References}

[1] Khorram, S. and M. Jafari, Pinpointing the key parameters that control the errors in estimating the total-load sediment flux using sand particles measured data in reservoir engineering. Journal of Petroleum Science and Engineering, 2010. 74(3-4): p. 163-170.

[2] Ran, L., et al., Cumulative sediment trapping by reservoirs in large river basins: A case study of the Yellow River basin. Global and Planetary Change, 2012.

[3] Hwang, S.-J., et al., Moderating effects of the geometry of reservoirs on the relation between urban land use and water quality. Landscape and Urban Planning, 2007. 82(4): p. 175-183.

[4] Palmieri, A., F. Shah, and A. Dinar, Economics of reservoir sedimentation and sustainable management of dams. Journal of Environmental Management, 2001. 61(2): p. 149-163.

[5] Verstraeten, G., et al., Sediment yield variability in Spain: a quantitative and semi qualitative analysis using reservoir sedimentation rates. Geomorphology, 2003. 50(4): p. 327-348.

[6] Rossi, A., et al., The response of the Mississippi River to climate fluctuations and reservoir construction as indicated by wavelet analysis of stream flow and suspended-sediment load, 19501975. Journal of Hydrology, 2009. 377(3-4): p. 237-244.

[7] Nguyen, V.P., V.T. Vu, and T.X. Tran, Water resources in Vietnam. Vietnamese Institute of Metro-hydrology. Agricultural Editor (in Vietnamese), 2003.

[8] Ranzi, R., T.H. Le, and M.C. Rulli, A RUSLE approach to model suspended sediment load in the Lo River (Vietnam): Effects of reservoirs and land use changes. Journal of Hydrology, 2012. 422-423(0): p. 17-29.

[9] Hamilton, D.P. and S.G. Schladow, Prediction of water quality in lakes and reservoirs. Part I-Model description. Ecological Modelling, 1997. 96(1): p. 91-110.

[10] NPC, The Population and Housing Census of the Federal Republic of Nigeria: Priority Tables. 2006, The National Population Commission.

[11] Yakubu, M.L. and H.A. Daura, Comparative study of alum and four other selected coagulants in the removal of raw water turbidity. Techno Science Africana Journal 2011. Volume 6: p. $125-129$.

[12] Report, S., Water supply and sanitation baseline survey, I.E. Associates, Editor. 2008, Department of water supply.

[13] Main, H.A., Dam projects and urbanization in Kano state, Nigeria. Singapore Journal of Tropical Geography, 1991. 11(2): p. 87-99.

[14] Tanko, A.I., Chapter 93: Mega dams for Irrigation in Nigeria, Nature, Dimensions, and Geographies of Impacts, in Engineering Earth: The Impacts of Mega engineering Projects, S.D. Brunn, Editor. 2011, Springer.

[15] Abdullahi, M.A., Engineering measures for the development of surface water resources in Kano state, in 6th WEDC: Water and Wastewater in Africa. 1980. p. 74-79.

[16] Levec, F. and A. Skinner, Manual of Instructions Bathymetric Surveys, M.O.N. Resources, Editor. 2004: Ontario. p. 27.

[17] World Commission of dams. Dams and Development: A New Framework for Decisionmaking: the Report of the World Commission on Dams, November 2000. 2000

[18] Ahmed, K. The Kano Physical Environment. 2011. 